Check for updates

Cite this: RSC Adv., 2017, 7, 23149

Received 21st February 2017

Accepted 23rd March 2017

DOI: 10.1039/c7ra02182h

rsc.li/rsc-advances

\title{
Synthesis and characterization of a high temperature thermosetting polyimide oligomer derived from a non-toxic, sustainable bisaniline
}

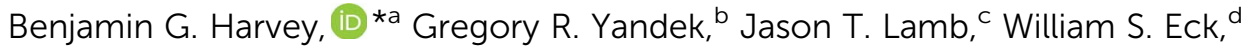 \\ Michael D. Garrison ${ }^{a}$ and Matthew C. Davis ${ }^{a}$
}

PMR-15 is a high temperature thermosetting polyimide oligomer widely used in aircraft engines, rocket casings, bushings, and bearings. Unfortunately, PMR-15 is prepared from the mutagenic and hepatotoxic compound methylene dianiline (MDA). To develop a safer alternative to PMR-15, an alternative thermosetting polyimide oligomer (PMR-PCy) was prepared from a less toxic bisaniline, 4,4'-methylenebis-(5-isopropyl-2-methylaniline) (CDA), derived from the renewable aromatic compound $p$-cymene. The thermoset network prepared from PMR-PCy had a glass transition temperature $\left(T_{\mathrm{g}}\right)$ of $323{ }^{\circ} \mathrm{C}$ as measured by differential scanning calorimetry (DSC), good thermooxidative stability, and water uptake of only 3\% after immersion in boiling water for $24 \mathrm{~h}$. The Quantitative Structure Activity Relationship (QSAR)-predicted low toxicity of CDA was confirmed by in vitro testing for mutagenicity, acute toxicity, and aquatic toxicity. CDA was found to be nonmutagenic in the Ames test, had a predicted $L D_{50}$ of $725 \mathrm{mg} \mathrm{kg}^{-1}$ in rats, and an $E_{50}$ of $299.3 \mathrm{mg}$ $\mathrm{L}^{-1}$. These results suggest that CDA is not acutely toxic to humans and has minimal to no aquatic toxicity. The combination of exceptional material properties coupled with the low toxicity of CDA suggest that PMR-PCy may be a viable non-toxic replacement for PMR-15 in a variety of aerospace applications.

\section{Introduction}

Methylene dianiline (MDA) is widely used in polyurethanes, as a hardener for epoxy resins, and as a component of high temperature thermosetting polyimide resins for aerospace applications. $^{1,2}$ One of the most important of these polyimide resins is PMR-15 ${ }^{3-5}$ which is prepared by mixing MDA, $3,3^{\prime}, 4,4^{\prime}$ benzophenonetetracarboxylic dianhydride (BTDA) and 5norbornene-2,3-dicarboxylic anhydride (NA) in a $2: 2: 3$ ratio of BTDA : NA : MDA to form amic acids which can then be thermally imidized to generate well defined polyimide oligomers endcapped with NA (Scheme 1). Further heating at temperatures in the range of $280-315{ }^{\circ} \mathrm{C}$ under pressure then generates a highly cross-linked network. The $T_{\mathrm{g}}$ of PMR-15 has been reported as ca. $340{ }^{\circ} \mathrm{C}^{6}$ and the material has outstanding longterm oxidative stability at $316^{\circ} \mathrm{C}^{5}$

\footnotetext{
${ }^{a} U S$ NAVY, NAWCWD, Research Department, Chemistry Division, China Lake, California 93555, USA. E-mail: benjamin.g.harvey@navy.mil

${ }^{b}$ Air Force Research Laboratory, Rocket Propulsion Division, Edwards AFB, California 93524, USA

${ }^{C} E R C$, Inc., Air Force Research Laboratory, Rocket Propulsion Division, Edwards AFB, California 93524, USA

${ }^{d}$ Army Public Health Center, Aberdeen Proving Ground, MD 21010, USA
}

One drawback of PMR-15 is its reliance on MDA as a significant component of the formulation. MDA is a potent liver toxicant with an occupational exposure limit (OEL) of only 10 ppb averaged over an 8 hour workday. ${ }^{7,8}$ MDA is also mutagenic, has been shown to be carcinogenic in mice, and is a suspected human carcinogen. ${ }^{9}$ Identifying and implementing a replacement for MDA that is less toxic is anticipated to reduce the occupational health impacts associated with MDA exposure, decrease liability for manufacturers that utilize MDA in their products, and provide a commercially sustainable bisaniline alternative.

A number of bisanilines with reduced toxicity have been investigated as replacements for MDA in PMR-polyimides. For example, Delvigs et al. studied four-ring diamines containing carbonyl groups and flexible ether and sulfur linkages. ${ }^{10}$ Three ring systems were reported by the same researchers in $1997 .{ }^{11}$ Pater and co-workers studied lower toxicity PMR formulations based on 3,4'-oxydianiline. ${ }^{\mathbf{1 2}, 13}$ However, many of these early replacements had lower $T_{\mathrm{g}} \mathrm{s}$ and thermal oxidative stability than PMR-15. To address these issues, researchers studied and patented the utilization of mixtures of non-toxic, flexible, multi-ring bisanilines in combination with single ring bisanilines. ${ }^{14}$ In addition to multi-ring systems, fluorinated MDA derivatives were studied as components of PMR-formulations in 2001. ${ }^{6}$ The fluorinated derivatives were shown to be non- 


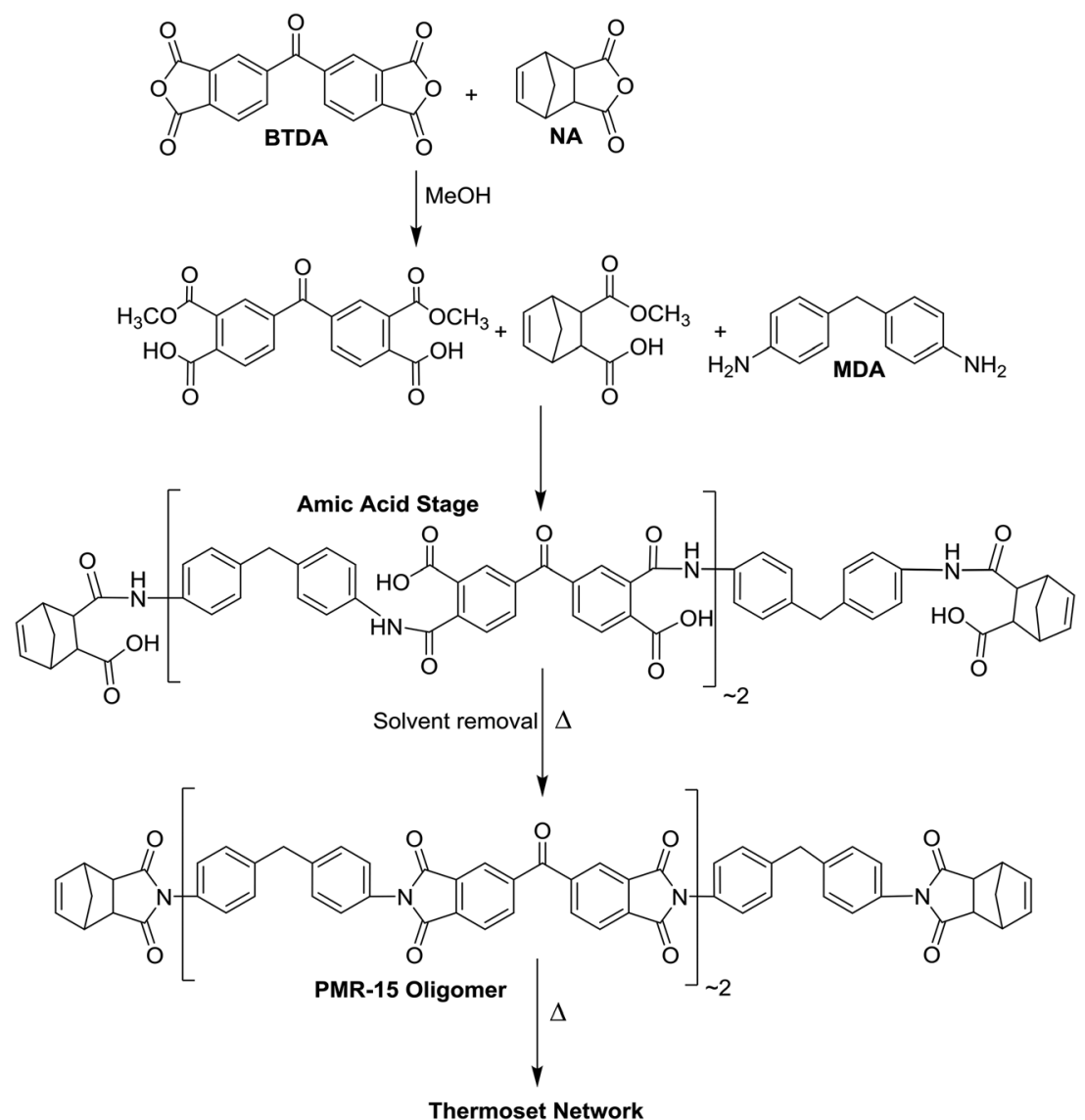

Scheme 1 Synthesis of PMR-15.

mutagenic and cured networks had comparable $T_{\mathrm{g}} \mathrm{s}$ to PMR15, but exhibited higher isothermal weight loss. The aggregate of efforts seeking to develop MDA alternatives demonstrates the importance of this monomer for advanced material applications and justifies the continued exploration of less toxic alternatives.

Although a number of synthetic routes to bisanilines with reduced toxicity can be envisioned, a compelling method is to utilize the structural diversity of renewable aromatic compounds to prepare bisanilines that have decreased toxicity while delivering the same properties as MDA. $p$-Cymene is a readily available aromatic compound that can be derived from pine resin or prepared by dehydrogenation of $\alpha$-pinene, $\beta$ pinene, and limonene..$^{15-19}$ Recent reports have also shown that $p$-cymene can be obtained by deoxygenation of terpenoid ethers. $^{20,21}$ Other researchers have shown that several of these terpene feedstocks and $p$-cymene itself can be prepared biosynthetically from biomass sugars. ${ }^{22-24}$ Long term production of $p$-cymene is therefore not limited to the availability of turpentine. Recent work by our group has shown that the $p$ cymene moiety imparts unique properties to thermosetting resins. For example, epoxy amine thermoset networks prepared from a bisaniline (CDA, Scheme 2) and epoxy monomer, both derived from $p$-cymene, showed substantially lower water uptake and a reduced "wet" $T_{\mathrm{g}}$ knockdown compared to a baseline system comprised of DGEBA and MDA. ${ }^{25}$ Further, a cyanate ester thermoset network containing the $p$-cymene moiety was shown to have one of the lowest water uptakes ever observed for a polycyanurate. ${ }^{26}$ Thus, the $p$-cymene structure has the potential to reduce the water uptake of thermosetting polyimides and improve hot-wet mechanical properties.

Although the effects of the aliphatic substituents on the mutagenicity and carcinogenicity of CDA have not previously been explored, studies with other alkyl-substituted bisanilines ${ }^{27,28}$ suggested that CDA would be a good candidate as a less toxic MDA replacement.

To determine the suitability of CDA as a replacement for MDA in a PMR-type formulation, this paper describes the synthesis of thermoset networks from CDA, BTDA and NA. The characterization of these networks and comparison to those prepared from MDA is then presented. Results for in vitro acute and aquatic toxicity and Ames mutagenicity testing of the CDA monomer are then discussed.

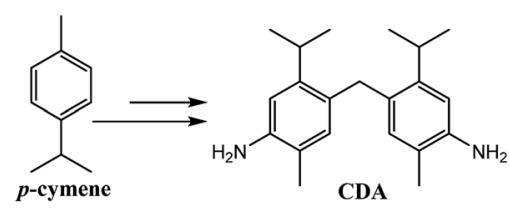

Scheme 2 Conversion of $p$-cymene to CDA. 


\section{Materials and methods}

\section{General}

Methanol and tetrahydrofuran (THF) were obtained from Fisher Scientific and used as received. 3,3',4,4'-Benzophenonetetracarboxylic dianhydride (BTDA) and 5-norbornene-2,3dicarboxylic anhydride (NA) were obtained from SigmaAldrich and stored in a glove box prior to use. 4,4'-Methylene dianiline (MDA) was obtained from Sigma-Aldrich and used as received. 4,4'-Methylenebis-(5-isopropyl-2-methylaniline) (CDA) was prepared as previously described. ${ }^{25}$ No living animals were used in the performance of this research. All toxicological testing was conducted in in vitro systems employing cells of either bacterial or eukaryotic origin. All relevant laws and regulations were followed.

\section{Synthesis of a PMR resin from 4,4'-methylenebis-(5-isopropyl- 2-methylaniline)}

In a dry, $\mathrm{N}_{2}$-filled glove box, BTDA ( $\left.0.7825 \mathrm{~g}, 2.43 \mathrm{mmol}\right)$ and NA $(0.3995 \mathrm{~g}, 2.44 \mathrm{mmol})$ were added to a $25 \mathrm{~mL}$ round-bottomed flask. The flask was removed from the glove box and $\mathrm{MeOH}$ $(8.5 \mathrm{~mL})$ was added. The mixture was stirred and refluxed for $2 \mathrm{~h}$, during which time the anhydride powders dissolved and the solution turned pale yellow. The solution was then left to cool to ambient temperature. CDA (1.1659 g, $3.76 \mathrm{mmol})$ was then added to the solution. The bisaniline rapidly dissolved and the solution transitioned to a darker yellow/amber shade. The solution was left to stir overnight and the solvent was then evaporated to yield $2.240 \mathrm{~g}$ of a bright yellow amic acid powder. $1.7986 \mathrm{~g}$ of the powder was heated in an oven at $200^{\circ} \mathrm{C}$ for $2 \mathrm{~h}$ in air followed by $30 \mathrm{~min}$ at $230{ }^{\circ} \mathrm{C}$ to imidize.

\section{Cross-linking of the PMR resin}

A 0.5 in diameter cylindrical compression mold was charged with $0.3502 \mathrm{~g}$ of imide powder. A piston was inserted into the cylinder and the mold was placed into a 1 ton heated press to cure. With minimal pressure applied (just enough to contact the mold assembly to allow heating from the top and bottom), the temperature was ramped from ambient temperature to $280{ }^{\circ} \mathrm{C}$ at $5.5{ }^{\circ} \mathrm{C} \mathrm{min}^{-1}$. A pressure of $184 \mathrm{psi}$ was applied while the temperature was further ramped to $315{ }^{\circ} \mathrm{C}$ at $0.5{ }^{\circ} \mathrm{C} \mathrm{min}{ }^{-1}$. The temperature and pressure were held for $90 \mathrm{~min}$ and then the mold was allowed to cool to ambient temperature. A solid, dark brown-colored, disc weighing $0.339 \mathrm{~g}$ was recovered for further analysis.

\section{Characterization}

\section{Differential scanning calorimetry (DSC)}

DSC experiments were performed with a TA Instruments Q200 DSC. T-zero DSC pans were loaded with $10-20 \mathrm{mg}$ of imide powder and the experiments were conducted under a nitrogen atmosphere. An initial ramp from ambient temperature up to $250{ }^{\circ} \mathrm{C}$ at $10{ }^{\circ} \mathrm{C} \mathrm{min}^{-1}$ was performed to eliminate any residual solvent or water and to allow the powder to flow and form good contact with the bottom of the pan. The samples were then equilibrated at $40{ }^{\circ} \mathrm{C}$ and ramped again at $10{ }^{\circ} \mathrm{C} \mathrm{min}^{-1}$ to $315{ }^{\circ} \mathrm{C}$. The material was then held isothermally for $2 \mathrm{~h}$ to promote cure, consistent with the typical cycle for PMR-15. Lastly, after equilibration at $40{ }^{\circ} \mathrm{C}$, a ramp to $400{ }^{\circ} \mathrm{C}$ at $10{ }^{\circ} \mathrm{C}$ $\min ^{-1}$ was utilized to measure the cured $T_{\mathrm{g}}$.

\section{Thermal gravimetric analysis (TGA)}

TGA experiments were performed using a TA Instruments Q5000 TGA under either air or nitrogen atmospheres. Temperature ramps were between $25{ }^{\circ} \mathrm{C}$ and $900{ }^{\circ} \mathrm{C}$ at a rate of $10^{\circ} \mathrm{C}$ $\min ^{-1}$. The temperatures at which $5 \%$ weight loss occurred (denoted $T_{\mathrm{d}, 5}$ ) were measured using the reduced mass obtained after curing was complete.

\section{Rheology}

Rheological experiments were performed with a TA Instruments Discover DHR3 rheometer. Samples were prepared by compressing powder into 1 in diameter disks. The test configuration consisted of two $25 \mathrm{~mm}$ stainless steel parallel plates situated at a gap of $0.750 \mathrm{~mm}$. The shear rate dependent viscosity of each material was recorded at $250{ }^{\circ} \mathrm{C}$ between 0.001 and $100 \mathrm{~s}^{-1}$. This temperature was chosen because it is above the $T_{\mathrm{g}}$ of the oligomers yet the nadic end-cap reactivity is low enough as to not noticeably affect the viscosity profiles.

\section{Thermomechanical analysis (TMA)}

TMA experiments were carried out on a TA Instruments Q400 TMA. A quartz expansion-type probe was used and the experiments were conducted under $\mathrm{N}_{2}$. An initial force of $0.20 \mathrm{~N}$ was set. The temperature was equilibrated at $100{ }^{\circ} \mathrm{C}$. Force was modulated at $0.05 \mathrm{~Hz}$ with an amplitude of $0.10 \mathrm{~N}$. The temperature was then cycled to $200{ }^{\circ} \mathrm{C}$ and back to $100{ }^{\circ} \mathrm{C}$ twice. The temperature was then ramped at $5{ }^{\circ} \mathrm{C} \min ^{-1}$ to $360-400{ }^{\circ} \mathrm{C}$, cooled at $5{ }^{\circ} \mathrm{C} \min ^{-1}$ to $100{ }^{\circ} \mathrm{C}$ and then ramped again at $5{ }^{\circ} \mathrm{C}$ $\min ^{-1}$ to $360-400{ }^{\circ} \mathrm{C}$. The $T_{\mathrm{g}}$ data given is from the final temperature ramp.

\section{Water uptake}

A $2 \mathrm{~L}$ Erlenmeyer flask was filled with approximately $1.75 \mathrm{~L}$ of de-ionized water and heated to boiling using a hot plate. Sample discs fabricated via compression molding were thoroughly dried in a vacuum oven for 3 days, weighed, and placed into the boiling water. For the first $7 \mathrm{~h}$, at approximately $1 \mathrm{~h}$ intervals, the samples were removed, blotted dry with Chem-wipes, blown dry with gaseous nitrogen, and weighed. The samples were then placed back into the water and the process was repeated until the eighth interval after which the samples were left overnight in boiling water before the final measurement.

\section{Thermal oxidative stability (TOS)}

The long-term thermal stability of the polyimide networks in air was quantified through conditioning of compression molded disks at $316{ }^{\circ} \mathrm{C}$ in a Lindberg Blue $\mathrm{M}$ tube furnace. The internal tube temperature was set to $316^{\circ} \mathrm{C}$. An air-generator fitted with a flow meter was connected to the tube such that a continuous 
flow rate of $100 \mathrm{~mL} \mathrm{~min}^{-1}$ of clean, filtered air flowed across the samples. The cured discs were situated on a graphite boat which was wrapped in aluminum mesh to support the discs and allow for air flow above and below the samples. Mass measurements of the discs were taken at 3-4 day intervals.

\section{Toxicity evaluation}

\section{Quantitative structure-activity (QSAR) evaluation}

Preliminary toxicity evaluations of the CDA monomer and MDA were conducted by QSAR analysis. Three QSAR packages were employed to obtain initial estimates of the biological properties of the monomer. Mammalian toxicity parameters were evaluated using the TOPKAT® QSAR modeling package, version 6.2. (TOPKAT is a registered trademark currently owned by BIOVIA Corp., San Diego, CA). Chemical structures were entered into the TOPKAT program as SMILES strings, and various toxicological endpoints were predicted along with confidence information. Of particular importance in this study were the predictions for acute oral and inhalation toxicity, mutagenicity, and developmental/reproductive toxicity. QSAR predictions are used to help guide the more important in vitro testing evaluations. In vitro tests can be conducted more rapidly and at less expense than full-scale animal in vivo testing.

\section{Neutral red uptake (NRU) cytotoxicity test}

The NRU test is an in vitro surrogate for in vivo acute oral toxicity testing based upon the ability of viable cells to incorporate and bind the supravital dye Neutral Red. Healthy mammalian cells, when maintained in culture, continuously divide and multiply over time. A toxic chemical can interfere with this process, resulting in a reduction of growth rate and ultimately cell death. Cytotoxicity is expressed as a concentration-dependent reduction of the uptake of Neutral Red after chemical exposure. Chang human liver CCL-13 cells, Eagle's Minimum Essential Medium (EMEM), and Fetal Bovine Serum (FBS) used in this assay were purchased from the American Type Culture Collection (Manassas, VA). The positive control, sodium lauryl sulfate, and other chemical reagents were purchased from SigmaAldrich. The CCL-13 cells were seeded into clear 96 well plates at $5.5 \pm 0.5 \times 10^{4}$ cells per $\mathrm{mL}$ and maintained in culture with the routine culture medium (e.g., EMEM-10\% FBS) in a $37{ }^{\circ} \mathrm{C} /$ $5 \% \mathrm{CO}_{2} / 100 \%$ humidity incubator for $24 \pm 1 \mathrm{~h}$ to form a semiconfluent monolayer. After the $24 \mathrm{~h}$ incubation, cultures were observed under the microscope for contamination and cell confluence prior to performing the chemical treatment. The cells were treated with test compounds by adding $0.1 \mathrm{~mL}$ of each concentration in serum-free EMEM medium per well and 0.1 $\mathrm{mL}$ of the medium per vehicle control well. The cultures were exposed to the test chemicals over a range of eight concentrations ( 6 wells per concentration) for $48 \pm 1 \mathrm{~h}$ at $37{ }^{\circ} \mathrm{C} / 5 \% \mathrm{CO}_{2} /$ $100 \%$ humidity. Next, cultures were observed under a microscope for contamination or precipitates. After examination, treatment medium was removed from the wells and $0.2 \mathrm{~mL}$ of phosphate buffered saline (PBS) was added to each of the wells and then aspirated. Neutral red medium (NRM) containing 33 $\mu \mathrm{g}$ dye per $\mathrm{mL}$ was added to each well ( $0.2 \mathrm{~mL}$ per well). After a $3 \mathrm{~h}$ incubation period, NRM was discarded and the cultures were washed once with PBS and then $0.1 \mathrm{~mL}$ of neutral red (NR) desorbing fixative was added to each well. The plates were placed on a shaker for $20 \mathrm{~min}$ at ambient temperature $\left(24 \pm 2{ }^{\circ} \mathrm{C}\right)$. NR absorption was detected at $540 \mathrm{~nm}$ in a Synergy HT Multi-Detection Microplate Reader. Plates were read using Gen5 $^{\mathrm{TM}}$ software (Synergy $^{\mathrm{TM}}$ HT Multi-Detection Microplate Reader, model SIAFRTD, BioTek Instruments, Inc, Winooski, VT).

\section{Ames mutagenicity test}

The Ames mutagenicity test was performed using a Xenometric MPF $^{\text {TM }}$ kit obtained from ANIARA (Mason, OH). The manufacturer's protocol was used to conduct the assay. The aqueous solubility limit of the chemical was the highest concentration tested. Each kit included Salmonella typhimurium strains TA98, TA100, TA1535, and TA1537, as well as a composite mix of Escherichia coli pKM101/uvrA strains. All reagents necessary for the conduct of the assay except DMSO (Aldrich) and water were included in the kit. The manufacturer's testing protocol was used. Briefly, each bacterial strain was exposed for $90 \mathrm{~min}$ to the serially diluted test compounds, solvent control, and positive control in the presence or absence of liver microsomes (S9 fraction) and then plated in triplicate into 384 well plates and incubated in reversion medium for $48 \mathrm{~h}$. Individual bacteria that have a mutagenic event within the histidine gene are able to survive and divide in the reversion medium. Wells are scored as negative or positive based on a pH-dependent color shift in the medium from purple (negative) to yellow (metabolically active bacteria).

Bacterial viability was measured by quantitating ATP after the 90 min exposure using a commercially available kit (Bactiter-glo, Promega Corp, Madison WI). The test is based upon the ability of test compounds to permit growth of the bacterial test systems in a histidine-free medium after inducing mutations in bacterial strains that are incapable of reproducing in the absence of endogenous histidine.

\section{In vitro aquatic toxicity testing (Microtox $\left.{ }^{\circledR}\right)$}

Microtox ${ }^{\circledR}$ is an acute toxicity testing system that uses a strain of naturally occurring luminescent bacteria, Alivibrio fischeri. The bioluminescence is tied directly to cellular respiration which is fundamental to cellular metabolism and associated life processes. These non-pathogenic marine bacteria are sensitive to a broad range of toxicants, resulting in a decreased rate of respiration and a corresponding decrease in the rate of luminescence. Reduction of the microorganism's light emission is proportional to the toxicity expressed as $\mathrm{EC}_{50}$ (the midpoint of the effective concentration). In the United States it is a recognized test method in a number of federal programs. Microtox test kits were purchased from Modern Water, Inc., New Castle, DE. The zinc sulfate positive control was purchased from SigmaAldrich. Assays were conducted using the Microtox ${ }^{\circledR}$ Model 500 Analyzer with proprietary MicrotoxOmni ${ }^{\mathrm{TM}}$ software. 


\section{Results and discussion}

PMR-PCy polyamic acid was synthesized from CDA, BTDA, and NA in an analogous manner to that of PMR-15. No alterations in the synthetic procedure were required as CDA was readily soluble in methanol. The resulting amic acid was then imidized under standard conditions $\left(200{ }^{\circ} \mathrm{C}\right.$ for $2 \mathrm{~h}, 230^{\circ} \mathrm{C}$ for an additional $30 \mathrm{~min}$ ) to yield an orange oligoimide powder. The cure chemistry of the oligomer was first analyzed by DSC (Fig. 1). The oligomer exhibited a pre-cure $T_{\mathrm{g}}$ of $192{ }^{\circ} \mathrm{C}$, slightly lower than PMR-15 $\left(200^{\circ} \mathrm{C}\right)$. After PMR-PCy was cured at $315^{\circ} \mathrm{C}$ for $2 \mathrm{~h}$, a $T_{\mathrm{g}}$ of $323{ }^{\circ} \mathrm{C}$ was observed, while a cured PMR-15 oligomer gave a $T_{\mathrm{g}}$ of $341{ }^{\circ} \mathrm{C}$. The latter is consistent with previous reports. ${ }^{6}$ The lower observed $T_{\mathrm{g}}$ for PMR-PCy was expected based on the slightly lower volumetric cross-link density due to the extra aliphatic groups. This slight decrease in $T_{\mathrm{g}}$ was in stark contrast to that previously observed for a cyanate ester with similar aliphatic groups ${ }^{26}$ and related epoxy-amine networks, ${ }^{25}$ which exhibited decreases of $\mathrm{ca} .60{ }^{\circ} \mathrm{C}$ and $30{ }^{\circ} \mathrm{C}$, respectively. This difference in behavior is due to the $p$-cymene moiety exerting greater concentration dependence in the cyanurate network because it is a single monomer system. Similarly, in the case of the epoxy network, both the epoxy monomer and curative were derived from $p$-cymene. In contrast, PMR-PCy contains two other monomer species (BTDA and NA) that contribute to the network composition. Further, the $T_{\mathrm{g}}$ of PMR-PCy is highly dependent on the cross-link density which is a function of the nadic end-cap.

In addition to the $T_{\mathrm{g}}$, three other features are notable in the DSC thermograms. The onset cure temperature for PMR-PCy appears to occur at a lower temperature and the initial cure reaction is more exothermic than PMR-15. PMR-PCy qualitatively exhibits a higher heat capacity than PMR-15, and for both materials, as expected, heat capacity decreases when crosslinked. Lastly, for both materials, degradation occurs nearly immediately after their respective $T_{\mathrm{g}} \mathrm{s}$, and the degradation onset for PMR-PCy occurs at $\sim 10{ }^{\circ} \mathrm{C}$ lower temperature at the prescribed scan rate. The results from further stability experiments are presented in subsequent paragraphs.

The $T_{\mathrm{g}}$ of the cross-linked polyimide was also probed by TMA and results similar to those measured by DSC were obtained

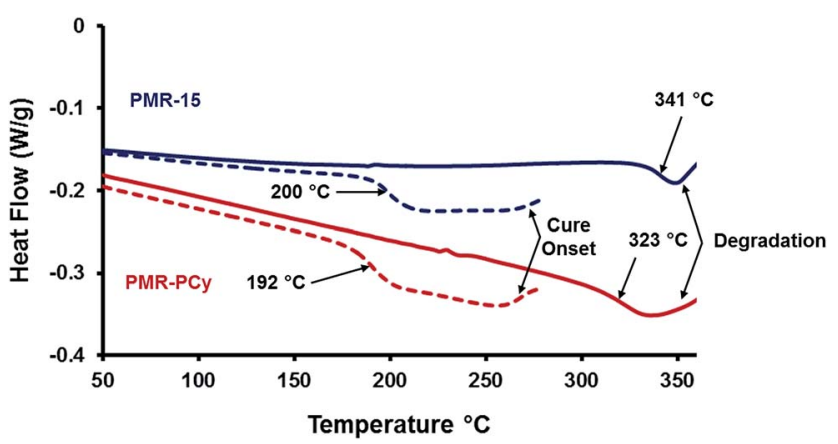

Fig. 1 Pre- and postcure DSC data for PMR-15 and PMR-PCy. The dashed lines are for the pre-cured oligomers and the solid lines are for the cross-linked networks.
Table 1 TMA data for PMR-15 and PMR-PCy

\begin{tabular}{lll}
\hline$T_{\mathrm{g}}$ method & PMR-15 $\left(T_{\mathrm{g}},{ }^{\circ} \mathrm{C}\right)$ & PMR-PCy $\left(T_{\mathrm{g}},{ }^{\circ} \mathrm{C}\right)$ \\
\hline Storage modulus & 343 & 330 \\
Loss modulus & 366 & 338 \\
Tan $\delta$ & 374 & 343 \\
Dimensional & 319 & 316 \\
change & &
\end{tabular}

(Table 1). For example, the $T_{\mathrm{g}}$ determined based on the loss modulus of the bio-based polyimide was $338{ }^{\circ} \mathrm{C}$ compared to $366{ }^{\circ} \mathrm{C}$ for PMR-15. Interestingly, the dimensional change temperature of PMR-PCy was within $3{ }^{\circ} \mathrm{C}$ of PMR-15 suggesting that the use temperatures of these two resins could be quite similar in practice.

To evaluate comparative processing parameters for the fabrication of neat resin specimens and composite materials, the complex viscosity dependence on deformation frequency of both PMR-PCy and PMR-15 was measured at $250{ }^{\circ} \mathrm{C}$ and is compared in Fig. 2. Both materials feature very similar complex viscosity profiles, suggesting that PMR-PCy can be processed in the same manner as PMR-15, and also revealing that the synthesis of both oligomers affords very similar molecular weight distributions.

To evaluate the thermal stability of PMR-PCy in comparison with PMR-15, the imidized powder was subjected to thermal gravimetric analysis under a nitrogen atmosphere (Fig. 3). The materials were ramped from ambient temperature up to $315{ }^{\circ} \mathrm{C}$ at $10{ }^{\circ} \mathrm{C} \mathrm{min}^{-1}$ and then held isothermally for $90 \mathrm{~min}$ to promote cross-linking. The temperature was then ramped to $900{ }^{\circ} \mathrm{C}$ at $10{ }^{\circ} \mathrm{C} \mathrm{min}^{-1}$. The decomposition temperature $T_{\mathrm{d}, 5}$, defined as the temperature at which $5 \%$ weight loss occurred after the curing step, was measured for PMR-15 and PMR-PCy using the mass of the cross-linked oligomer as the baseline. PMR-PCy showed greater mass loss than PMR-15 at temperatures below $300{ }^{\circ} \mathrm{C}$ suggesting that imidization was not completed during the initial cure reaction in the oven. It is likely that the increased steric hindrance near the amine functionality

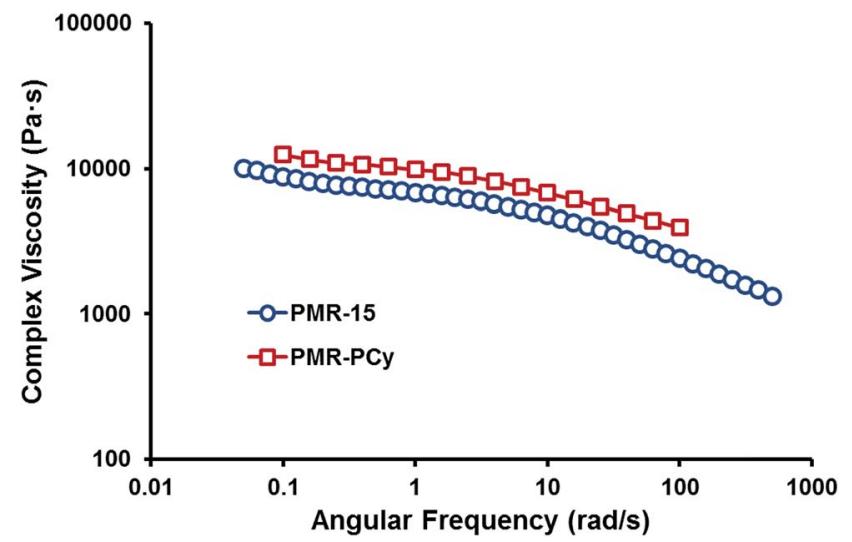

Fig. 2 Complex viscosity of PMR-15 and PMR-PCy as a function of deformation frequency. 


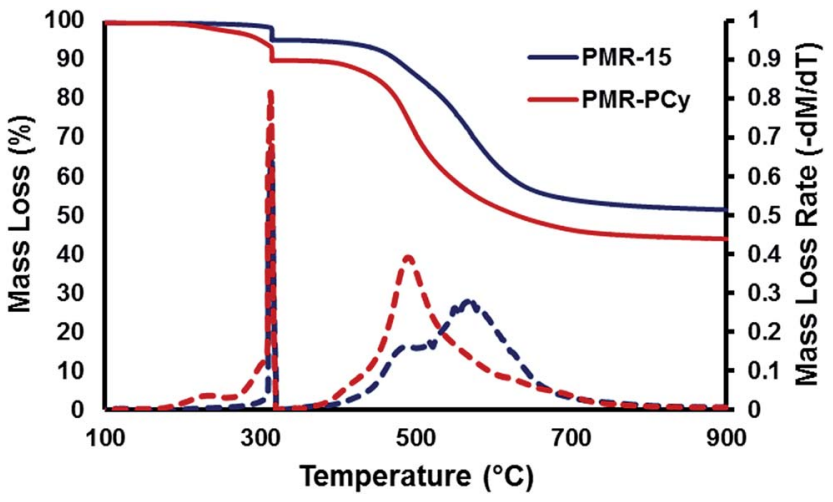

Fig. 3 Thermal-induced mass loss (solid lines) and loss rates (dashed) for PMR-15 and PMR-PCy in nitrogen, as measured by TGA.

in PMR-PCy results in a slower imidization reaction rate. However, after full imidization, both materials show excellent stability at $315{ }^{\circ} \mathrm{C}$ during the curing step, only losing approximately $3 \%$ of their weight, which is likely due to the evolution of cyclopentadiene. ${ }^{29,30}$ PMR-15 exhibited greater thermal stability under both air and nitrogen, with PMR-PCy being particularly sensitive to decomposition in air (Table 2). A similar effect was observed for a cyanate ester with analogous aliphatic functionality, ${ }^{26}$ suggesting that the methyl and isopropyl groups on the aromatic rings are sites for initial thermal degradation.

The thermal stability of the polyimides was further studied by a long term thermal oxidation study (TOS) conducted under isothermal conditions. Cured resin disks were placed into an oven at $316^{\circ} \mathrm{C}$ under flowing air and the weight loss of the disks was measured over the course of $670 \mathrm{~h}$ (Fig. 4). Similar to the results obtained from the TGA study, PMR-PCy demonstrated lower thermal stability losing $3.4 \%$ of its mass after $670 \mathrm{~h}$, while PMR-15 lost only 1.9\%. In general, the TOS results for PMR-PCy were quite promising given that the TOS study was conducted at a temperature approaching the $T_{\mathrm{g}}$ of PMR-PCy. Further, the overall weight loss for composites fabricated from these resin systems would be greatly decreased as the resin content would only be about $35 \%$.

Thermosetting polyimides have a tendency to absorb significant quantities of water due to the presence of a number of carbonyl groups and tertiary amines that can readily hydrogen bond with water. As a result, water uptake can degrade mechanical properties and lead to catastrophic failure of composite materials in aerospace applications due to delamination. The $p$-cymene structure has previously been shown to greatly reduce water uptake in both cyanate esters and epoxy-amine networks. ${ }^{25,26}$ To evaluate the hydrophobicity of PMR-PCy, cured resin disks of PMR-PCy and PMR-15 were

Table 2 Decomposition temperatures of polyimides

\begin{tabular}{lll}
\hline Conditions & PMR-15 & PMR-PCy \\
\hline$T_{\mathrm{d}, 5}\left(10^{\circ} \mathrm{C} \mathrm{min}^{-1}, \mathrm{~N}_{2}\right)$ & 473 & 448 \\
$T_{\mathrm{d}, 5}\left(10^{\circ} \mathrm{C} \mathrm{\textrm {min } ^ { - 1 } , \text { air } )}\right.$ & 476 & 427
\end{tabular}

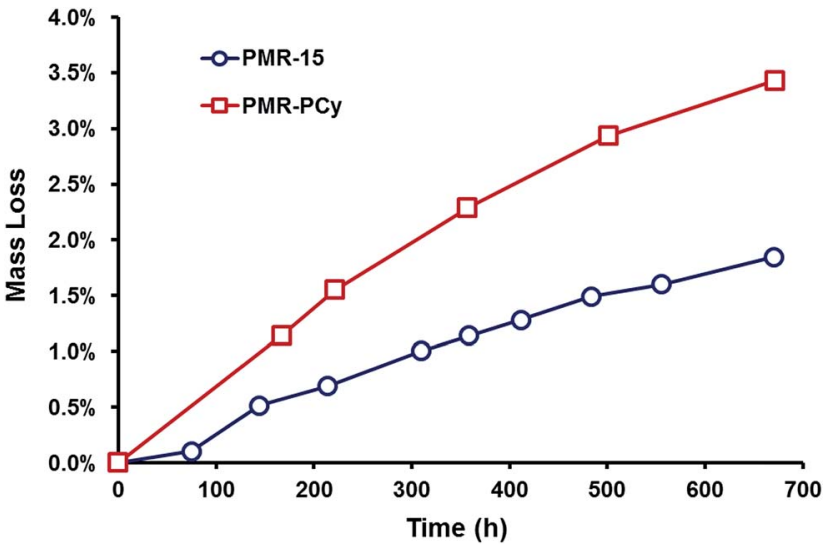

Fig. 4 Long term TOS data for cross-linked PMR-15 and PMR-PCy.

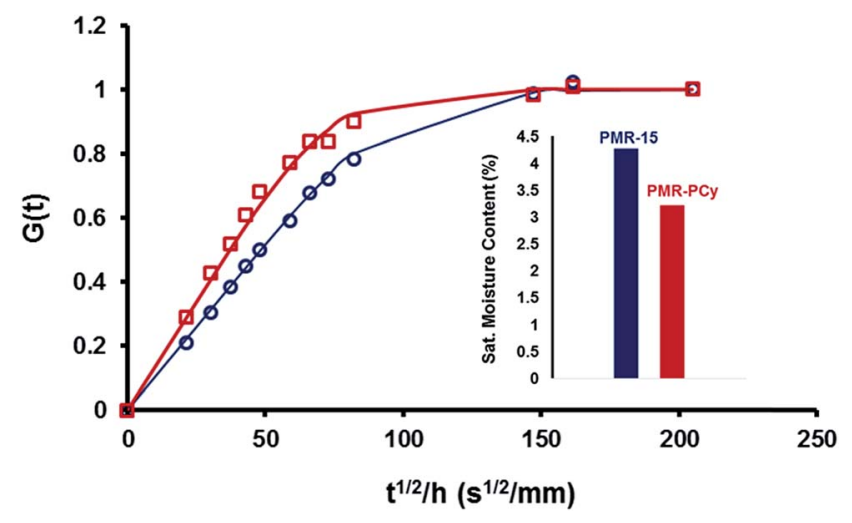

Fig. 5 Normalized water sorption data, $G(t)$ (symbols), and fits derived from the Fickian diffusion model (lines) for cross-linked PMR-15 and PMR-PCy.

placed in boiling water for $24 \mathrm{~h}$. PMR-PCy exhibited a mass gain of only $3.2 \%$ compared to $4.5 \%$ for PMR-15 (Fig. 5 , inset). Time dependent mass data was analyzed via a Fickian diffusion model from which diffusion coefficients $(D)$ were measured. $D$ for PMR-15 is $2.9 \times 10^{-5} \mathrm{~mm}^{2} \mathrm{~s}^{-1}$, while that of PMR-PCy is 5.0 $\times 10^{-5} \mathrm{~mm}^{2} \mathrm{~s}^{-1}$. The increased rate of water diffusion into the network prepared from PMR-PCy is attributed to its lower density with respect to PMR-15. However, PMR-PCy has 29\% lower net water uptake than PMR-15 due to the volume occupation of isopropyl and methyl groups on the aniline's phenyl rings.

\section{Toxicity evaluation}

Despite the promising properties of PMR-PCy, the toxicity of CDA was an open question. As a first step toward predicting its toxicity, QSAR methods were utilized to estimate key parameters including mutagenicity, carcinogenicity, oral and inhalation toxicity as well as the $\mathrm{EC}_{50}$ and $\mathrm{LC}_{50}$ for various organisms. The QSAR results suggested that CDA would have very low oral and inhalation toxicity, but did not provide any insight into the mutagenicity or carcinogenicity of CDA. Previous work by Rao 
and coworkers ${ }^{27}$ showed that aliphatic substitution at the ortho positions of bisanilines has a significant impact on mutagenicity as measured by the Ames test. ${ }^{28}$ Substitution of only one ortho position by small alkyl groups (Me, Et) actually increased the mutagenicity of the bisanilines compared to MDA, while substitution with an isopropyl group greatly reduced the mutagenicity. When both ortho positions were substituted with alkyl groups the bisanilines were found to be non-mutagenic regardless of the size of the alkyl groups. These results suggested that steric hindrance of the amine was important for decreasing mutagenicity, but it was not clear how the combination of an ortho methyl group and meta isopropyl group would impact the toxicity.

The toxicity of CDA was then evaluated using three complementary in vitro assays. Test results and predictions for both MDA and CDA are summarized in Table 3. The oral $\mathrm{LD}_{50}$ for rats was calculated from the NRU results with the following equation:

$$
\log \mathrm{LD}_{50}\left(\mathrm{mg} \mathrm{kg}^{-1}\right)=0.372 \log \mathrm{IC}_{50}\left(\mu \mathrm{g} \mathrm{mL}^{-1}\right)+2.024
$$

where $\mathrm{LD}_{50}$ is the median lethal dose and $\mathrm{IC}_{50}$ is the halfmaximal inhibitory concentration for uptake of the neutral red dye. CDA is predicted to have an oral $\mathrm{LD}_{50}$ of $725 \mathrm{mg} \mathrm{kg}^{-1}$ in rats, a value corresponding to Category 4 in the Globally Harmonized System (GHS), ${ }^{31}$ and indicating negligible toxicity. The predicted oral $\mathrm{LD}_{50}$ of MDA was found to be $944 \mathrm{mg} \mathrm{kg}^{-1}$, a similar value to that for CDA and also corresponding to Category 4 in the GHS. Ames testing revealed that CDA was nonmutagenic in all five of the Ames assay bacterial strains up to the cytotoxic concentration of $35 \mu \mathrm{g} \mathrm{mL}{ }^{-1}$. In contrast, MDA tested positive in the Ames assay. Finally, the predicted acute aquatic toxicity of CDA was measured by Microtox screening and the $\mathrm{EC}_{50}$ was found to be 299.3 (1.3) $\mathrm{mg} \mathrm{L}^{-1}$ which places it in the category of "non-toxic" according to the GHS. In contrast, MDA had an $\mathrm{EC}_{50}$ of $14.3 \mathrm{mg} \mathrm{L}{ }^{-1}$, revealing that its aquatic toxicity is more than 20 times higher than CDA.

The above results show that the steric hindrance provided by the isopropyl group meta to the aniline, in combination with the ortho methyl group, is sufficient to eliminate the mutagenicity of CDA. Similar bisanilines containing ortho alkyl groups and other bulky moieties in the meta position (e.g. $t$-butyl groups) would also be expected to be non-mutagenic. However,

Table 3 Comparison of computational predictions and in vitro test results for MDA and CDA

\begin{tabular}{|c|c|c|}
\hline Test method & MDA & CDA \\
\hline Oral $\mathrm{LD}_{50}$ QSAR prediction & $1900 \mathrm{mg} \mathrm{kg}^{-1}$ & $>10000 \mathrm{mg} \mathrm{kg}^{a}$ \\
\hline Acute oral $\mathrm{LD}_{50}(\mathrm{NRU})$ & $944 \mathrm{mg} \mathrm{kg}^{-1}$ & $725 \mathrm{mg} \mathrm{kg}^{-1}$ \\
\hline Ames mutagenicity (QSAR) & $\begin{array}{l}\text { Positive (TOPKAT } \\
\text { database value) }\end{array}$ & Indeterminate \\
\hline Ames mutagenicity (exp) & Positive & Negative \\
\hline Aquatic tox (Microtox) & $14.30 \mathrm{mg} \mathrm{L}^{-1}$ & $299.3 \mathrm{mg} \mathrm{L}^{-1}$ \\
\hline
\end{tabular}

based on the lower thermooxidative stability of PMR-PCy at $316^{\circ} \mathrm{C}$ compared to PMR-15, it is expected that thermosetting polyimides with greater aliphatic character than PMR-PCy would have unacceptable stability at elevated temperature. For aniline-based polymer systems that do not require exceptional thermooxidative stability (e.g. epoxy amine resins and polyurethanes), the general strategy of utilizing bisaniline monomers with bulky groups in the positions meta to the amine groups, may have merit. This approach could allow for the development of new high performance materials with reduced occupational and consumer health impacts.

\section{Conclusions}

A bisaniline (CDA) prepared from the sustainable aromatic compound $p$-cymene, was shown to be a less toxic alternative to MDA. The polyimide oligomer prepared from CDA, BTDA, and NA, denoted PMR-PCy, had a cured $T_{\mathrm{g}}$, as determined by dimensional change, only $3{ }^{\circ} \mathrm{C}$ lower than PMR-15. PMR-PCy also showed excellent long term stability at $316{ }^{\circ} \mathrm{C}$ in flowing air and featured a saturated water uptake $29 \%$ lower than PMR15. In addition to these outstanding physical properties, CDA was shown to be non-mutagenic in the Ames assay and was predicted to have negligible mammalian and aquatic acute toxicity based on in vitro surrogate assays. The starting material for CDA, $p$-cymene, can be isolated from pine resin and crude sulfate turpentine, or generated from biomass sugars by a combination of biosynthesis and chemical catalysis. This suggests that CDA can be sustainably produced on a commercial scale and may therefore represent a realistic alternative for MDA in polyurethanes, epoxy resins, and polyimides.

\section{Disclaimer}

The views expressed in this publication are those of the authors and do not necessarily reflect the official policy of the Department of Defense or any of its components. Use of trademarked names does not imply endorsement by the Department of Defense or any of its components, but is intended only to assist in identification of a specific product.

\section{Acknowledgements}

The authors would like to thank the Strategic Environmental Research and Development Program (SERDP WP-2402) for financial support of this work. The authors would also like to thank Ross Shingledecker for synthetic help and Dr John La Scala for helpful suggestions. In vitro toxicity testing was performed at the Army Public Health Center by Dr Valerie Adams (Ames test) and Dr Cheng Cao (NRU and Microtox test).

\section{References}

1 Merck Index 14th Edition, ed. M. J. O'Neil, P. A. Heckelman, C. B. Koch, K. J. Roman, Merck Research Laboratories, Whitehouse Station, NJ, 2006, p. 2976. 
2 T. A. Lewandowski, A. W. Hayes and B. D. Beck, Risk evaluation of occupational exposure to methylene dianiline and toluene diamine in polyurethane foam, Hum. Exp. Toxicol., 2005, 24, 655-662.

3 T. T. Serafini, P. Delvigs and G. R. Lightsey, Thermally stable polyimides from solutions of monomeric reactants, J. Appl. Polym. Sci., 1972, 16, 905-915.

4 T. T. Serafini, P. Delvigs, W. B. Alston, PMR polyimidesreview and update, Proceedings of the 27th National SAMPE Symposium and Exhibition, San Diego, CA, 1982, pp. 320-335.

5 D. Wilson, PMR-15 processing, properties and problemsa review, Br. Polym. J., 1988, 20, 405-416.

6 P. Delvigs, D. L. Klopotek and D. Hardy-Green, Addition polyimides from non-mutagenic diamines, High Perform. Polym., 2001, 13, 301-312.

7 T. Weiss, H. Schuster, J. Müller, K.-H. Schaller, H. Drexler, J. Angerer and H. U. Käfferlein, Dermal uptake and excretion of, 4,4'-methylenedianiline during rotor blade production in helicopter industry-an intervention study, Ann. Occup. Hyg., 2001, 1-7.

8 http://www.cdc.gov/niosh/npg/npgd0415.html accessed 05/ 03/2016.

9 (a) National Technology Program, 4,4'-Methylenedianiline and its hydrochloride, Rep. Carcinog., 2011, 12, 265-267; (b) X. Zhang, J. C. Lambert, M. A. Doll, J. M. Walraven, G. E. Arteel and D. W. Hein, 4,4'-Methylenedianilineinduced hepatotoxicity is modified by $N$-acetyltransferace 2 (NAT2) acetylator polymorphism in the rat, J. Pharmacol. Exp. Ther., 2006, 316, 289-294.

10 P. Delvigs, D. L. Klopotek and P. J. Cavano, Structureproperty relationships in addition polyimides. I: Resins from four-ring aromatic diamines containing carbonyl and methylene groups, High Perform. Polym., 1994, 6, 209-223.

11 P. Delvigs, D. L. Klopotek and P. J. Cavano, Structureproperty relationships in addition polyimides. II. Resins from three-ring aromatic diamines containing carbonyl and methylene groups, High Perform. Polym., 1997, 9, 161176.

12 T. H. Hou, S. P. Wilkinson, N. J. Johnston, R. H. Pater and T. L. Schneider, Processing and properties of IM7/LARC ${ }^{\text {TM }}$ RP46 polyimide composites, High Perform. Polym., 1996, 8, 491-505.

13 R. H. Pater, Low toxicity high temperature PMR polyimide, US Pat. 5171822, 1992.

14 R. A. Gray, Low-toxicity, high-temperature polyimides, US Pat. 6184333, 2001.

15 M. A. Martin-Luengo, M. Yates, M. J. M. Domingo, B. Casal, M. Iglesias, M. Esteban and E. R. Ruiz-Hitsky, Synthesis of $p$ cymene from limonene, a renewable feedstock, Appl. Catal., $B, 2008,81,218-224$.

16 M. A. Martin-Luengo, M. Yates, E. S. Rojo, D. H. Arribus, D. Aguilar and E. R. Hitzky, Sustainable $p$-cymene and hydrogen from limonene, Appl. Catal., A, 2010, 387, 141-146.

17 M. Kamitsou, G. D. Panagiotou, K. S. Triantafyllidis, K. Bourikas, A. Lycourghiotis and C. Kordulis,
Transformation of $\alpha$-limonene into $p$-cymene over oxide catalysts: a green chemistry approach, Appl. Catal., A, 2014, 474, 224-229.

18 B. G. Harvey, M. E. Wright and R. L. Quintana, High density renewable fuels based on the selective dimerization of pinenes, Energy Fuels, 2010, 24, 267-273.

19 H. A. Meylemans, R. L. Quintana and B. G. Harvey, Efficient conversion of pure and mixed terpene feedstocks to high density fuels, Fuel, 2012, 97, 560-568.

20 H. A. Meylemans, R. L. Quintana, M. L. Rex and B. G. Harvey, Low-temperature, solvent-free dehydration of cineoles with heterogeneous acid catalysts for the production of highdensity biofuels, J. Chem. Technol. Biotechnol., 2014, 89, 957-962.

21 B. A. Leita, A. C. Warden, N. Burke, M. S. O'Shea and D. Trimm, Production of $p$-cymene and hydrogen from a bio-renewable feedstock-1,8-cineole (eucalyptus oil), Green Chem., 2010, 12, 70-76.

22 S. Sarria, B. Wong, H. G. Martín, J. D. Keasling and P. PeraltaYahya, Microbial synthesis of pinene, ACS Synth. Biol., 2014, 3, 466-475.

23 F.-L. Du, H.-L. Yu, J.-H. Xu and C.-X. Li, Enhanced limonene production by optimizing the expression of limonene biosynthesis and MEP pathway genes in E. coli, Biores. Bioprocess., 2014, (10), 1, DOI: 10.1186/s40643-014-0010-z.

24 A. R. Tomsheck, G. A. Strobel, E. Booth, B. Geary, d. Spakowics, B. Knighton, C. Floerchinger, J. Sears, O. Liarzi and D. Ezra, Hypoxylon sp., an endophyte of Persea indica, producing 1,8-cineole and other bioactive volatiles with fuel potential, Microbiol. Ecol., 2010, 60, 903914.

25 M. D. Garrison and B. G. Harvey, Bio-based hydrophobic epoxy-amine networks derived from renewable terpenoids, J. Appl. Polym. Sci., 2016, 133, 43621.

26 B. G. Harvey, A. J. Guenthner, T. A. Koontz, P. J. Storch, J. T. Reams and T. J. Groshens, Sustainable hydrophobic thermosetting resins and polycarbonates from turpentine, Green Chem., 2016, 18, 2416-2423.

27 T. K. Rao, G. F. Dorsey, B. E. Allen and J. L. Epler, Mutagenicity of 4,4'-methylenedianiline derivatives in the salmonella histidine reversion assay, Arch. Toxicol., 1982, 49, 185-190.

28 B. N. Ames, J. McCann and E. Yamasaki, Methods for detecting carcinogens and mutagens with the salmonella/ mammalian-microsome mutagenicity test, Mutat. Res., 1975, 31, 347-364.

29 J. N. Hay, J. D. Boyle, S. F. Parker and D. Wilson, Polymerization of $N$-phenylnadimide: a model for the crosslinking of PMR-15 polyimide, Polymer, 1989, 30, 1032.

30 M. A. B. Meador, J. C. Johnston and P. J. Cavano, Elucidation of the cross-link structure of nadic-end-capped polyimides using NMR of ${ }^{13} \mathrm{C}$-labeled polymers, Macromolecules, 1997, 30, 515-519.

31 Hazardous Communications-Final Rule, Federal Register OSHA, 2012, vol. 77, no. 58, pp. 17790-17896. 